Models of care were not specifically prescribed, hospices' ICP commissioning arrangements meant that there were different starting points and local requirements, but it was agreed that measures of success might be:

- Number of patients supported and the number of interventions offered.

- Patients managed in preferred place of care.

- Number of hospital admissions and primary care interventions avoided.

Hospices also agreed to provide compelling patient stories to 'bring to life' the power of the work they could do as 'community anchor' organisations to support the wider system and to reduce health inequalities. Pilots were diverse and successful, many have now become part of core services.

\section{P-210 COVID-19 SILVER LININGS - ENHANCED COLLABORATION WITH HOSPICE PARTNERS}

${ }^{1}$ Alison Stevens, ${ }^{1}$ Matt Sweeting, ${ }^{2}$ Eileen Marshall, ${ }^{2}$ Joanne McCollum, ${ }^{3}$ Steve Smith, ${ }^{3}$ Ellie Miller, ${ }^{4}$ Pam Court, ${ }^{4}$ Tes Smith. ${ }^{1}$ Farleigh Hospice, Chelmsford, UK; ${ }^{2}$ St Luke's Hospice, Basildon, UK; ${ }^{3}$ Havens Hospices, Southend, UK; ${ }^{4}$ St Francis Hospice, Romford, UK

\subsection{6/spcare-2021-Hospice.225}

Background The COVID-19 pandemic, whilst challenging for all, acted as a catalyst for collaboration between NHS partners and hospice colleagues to improve service delivery across all settings.

The directors of care from four hospices met weekly with commissioners to provide support for one another and to work collaboratively to ensure increasing demands were met and good practice shared. This collaborative effort paid off with a successful joint bid for additional funding to enhance 24/7 care and support for care homes. Key outcomes were delivered and care enhanced through new and different ways of working.

Aim Our main aim is to learn from this experience to transform care for people receiving palliative and end-of-life care across our Integrated Care System. Emerging from the second wave, the four hospices were keen to learn from this experience, to optimise opportunities and improve quality of care for patients, their families and bereaved clients. A joint Hospice Collaboration Project group was set up with fortnightly meetings to develop key collaborative projects.

Methodology The group will work collaboratively to:

- Identify population health needs in relation to palliative and end-of-life care.

- Create a model of partnership which influences and shapes best practice, that is sustainable and maximises statutory and voluntary income to meet the outcomes of the needs analysis.

- Meet the requirements of the national, regional and local population health agendas.

- Share best practice and offer joint solutions where possible demonstrating the ongoing 'added value' of hospices in care delivery.

Results At this stage the project is at the outset of shaping a sustainable way ahead, working with system partners including the Palliative and End of Life Care Delivery Group and commissioners and learning from other hospice approaches. Our methodology has backing from the ICS and regional strategic clinical network.
Conclusions It's early days but there's great energy, inspiration and willingness for continued improvement to service delivery as demonstrated during the pandemic.

\section{P-211 LESSONS IN END-OF-LIFE COMMISSIONING: A BRAVE MOVE?}

Julie Barker. NHS Nottingham and Nottinghamshire, Nottingham, UK

\subsection{6/spcare-2021-Hospice.226}

Background Mid Nottinghamshire's population has a higher than average population of over $85 \mathrm{~s}$ and a steadily increasing death rate, set to increase by over $50 \%$ in the next 30 years (Popnat). Providing quality care for this cohort is a huge challenge to the NHS and social care.

Aims Mid Notts CCG contracted a joint contracting mechanism to test whether a combined contract could produce savings whilst increasing quality. End-of-life care including specialist palliative care was the second service to adopt this approach.

Methods Mid-Notts End of Life Care Together Alliance (EOLCT) was commissioned in 2016. With a collaboratively designed strategy we were given a $£ 3$ million envelope to provide services for a population of 356,000. A 10\% QUIPP target applied in the first year. The budget was ringfenced: surplus could be used to improve services.

One acute trust, ambulance trust, one community trust, two independent hospices, two third-sector organisations and primary care partnered together, with close engagement with social care.

A care-coordination service (Call4Care) was started and staffed 24/7 with access to specialist palliative care nurses. Five key metrics were agreed. Our GSF-based EPaCCS template was used by all community partners with notifications to EMAS and 111. The A\&E department had a readable version. EOLCT went live in October 2018.

Results EPaCCS (trend 2017-2020)

- Larger trusts provided financial assurance to third-sector partners.

- Earlier patient identification $(0.22-0.66 \%)$.

- Those on register DIUPR (54.7-87\%) with $61.9 \%$ overall. Nottinghamshire average fell to $56.6 \%$ during this time.

- Reduced hospitalisation and system savings.

- Better outcomes for individuals (commendations, fewer complaints).

Conclusion True partnership working arose from the process. The savings target was achieved and at a time where end-oflife admissions were rising, Mid Notts dropped. Further evaluation is planned with a view to possible further expansion.

\section{P-212 RESPLENDENT: A SYSTEM-WIDE MODEL OF COORDINATING A CRISIS RESPONSE AND TRANSFORMING CARE}

'Jon Devlin, '2Lisa Hancock. 'Greenwich and Bexley Community Hospice, London, UK; ${ }^{2}$ South East London CCG, London, UK

\subsection{6/spcare-2021-Hospice.227}

'Resplendent' is the Silver Command group which has met weekly, flexing to need, initially as an operational necessity to coordinate work in the first wave of COVID-19. Membership 